\title{
Efficient Parameter Reading of Electronic Charkha
}

\author{
Mayuri W. Meshram ${ }^{1}$, Mr. S. T. Valunjkar ${ }^{2}$ \\ M.Tech Student, Department of EDT, NIELIT, Aurangabad, Maharashtra, India ${ }^{1}$ \\ Scientist E, Department of EDT, NIELIT, Aurangabad, Maharashtra, India ${ }^{2}$
}

\begin{abstract}
The system proposed in this paper aims at monitoring the torque and efficiency in simple dc motors in real time by employing steel disc. An embedded system is employed for acquiring electrical signals from the motor in a noninvasive manner, and then performing local processing for torque and efficiency estimation. The values calculated by the embedded system are transmitted to a LCD. Motors can be monitored in real time. An experimental study was conducted for observing the electronic charkha with its conditioning parameters. This study demonstrated that the use of intelligent nodes, with local processing capability, is essential for this type of application. The embedded system was deployed on a charkha with disc arrangement and studies were conducted to analyze torque and system efficiency.
\end{abstract}

Keywords: Efficiency estimation, embedded systems, PMDC motors, torque measurement, steel disc.

\section{INTRODUCTION}

The charkha is a small device which can be used to spin fiber such as cotton into yarn. Fabric from this yarn can be used to make all sort of clothing. Increasing demands of the cotton fabrics, now-a-day has made it necessary to increase the production of cotton fabrics. Hence, DC motor helps to increases the production and also helps to handle the charkha in easy way.

In an industrial environment, Torque is one of the main parameters for production machines. In several industry sectors, torque measurements can identify equipment failure, which makes their monitoring essential in order to avoid disasters in critical production processes (e.g., oil and gas, mining, and sugar and alcohol industries). For decades, researchers have studied methods and systems for determining the torque in rotating shafts. There are basically two lines of study: direct torque measurement on the shaft, and estimated torque measurement from motor electrical signal. In most cases, the methods for direct torque measurement on the shafts are the more accurate.

However, they are highly invasive, considering the coup ling of the measurement instrument between the motor and the load. Moreover, some of these techniques still have serious operational challenges. The estimated torque from the motor's electrical signals (i.e., current and voltage) makes the system less invasive, but it is less accurate when compared to direct measurement systems. There are problems, such as noise in signal acquisition, those related to numerical integration, and low levels of voltage signals at low frequencies. However, in many cases, high precision is not critical, and low invasiveness is required. There are different methods to measure efficiency in induction motors, which are based on dynamometer, duplicate machines, and equivalent circuit approaches.

However, their application for in-service motors is impractical, because it requires interrupting the machine's operation to install the instruments. There are some simple methods for in-service efficiency estimation, like the nameplate method, the slip method, and the current method. These methods present as the main limiting factors the low accuracy, estimative based on nominal motor data and the need of typical efficiency-versus-load curves.

\section{LITERATURE REVIEW}

Hsu and Scoggins presented the air-gap torque [1] (AGT) for energy efficiency estimation. In, the AGT is also used to measure efficiency in a much less invasive manner. The AGT[1] method can be employed without interrupting the motor operation and it is not based on the motor nameplate. This method generally is more accurate than the other methods described earlier.

In this study, the AGT [2] method was used for the estimation of the motor shaft torque and efficiency [3], because it is the non-invasive method for determining torque and efficiency that has less uncertainty [4]. Traditionally, energy monitoring and fault detection in industrial systems are performed in an offline manner or through wired networks [5]. But I am using simple torque and efficiency estimation of electronic charkha. 

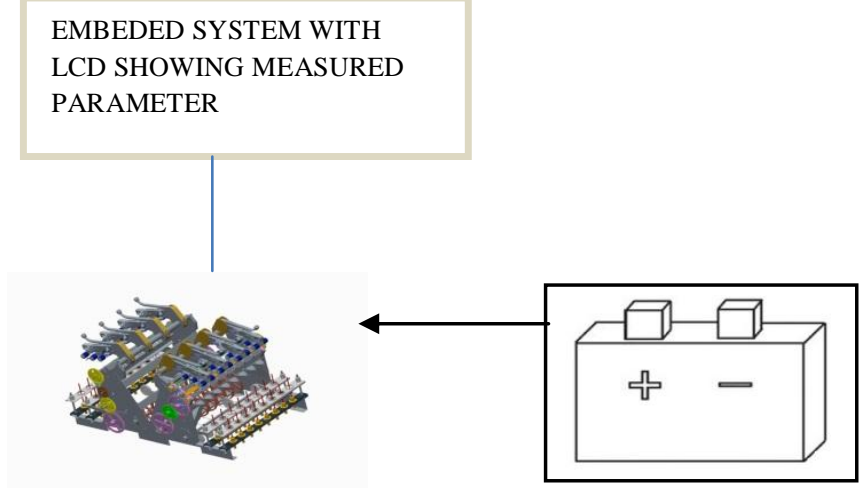

32 spinning units with DC motor

Battery

Fig.1.Proposed Block Diagram

\section{METHODOLOGY}

The efficient parameter of charkha proposed in this paper. The charkha with steel disc is composed by the embedded systems located close to the DC motors. The values of motor voltage and current are obtained from the sensors, and the embedded system performs the processing for determining the values of torque, speed, and efficiency. Information obtained after the processing are transmitted to LCD display. For current measurement, open loop Hall Effect current sensor is used. The main element of the embedded system is a PIC16F877A, which is a digital signal controller designed for applications such as machine control application, measurement device, study purpose and so on. Our requirement is for measurement. It has two integrated ADC, which perform simultaneous acquisition of the voltage and current sensors. The values of torque and motor efficiency are transmitted to LCD display using the infrared transceiver.

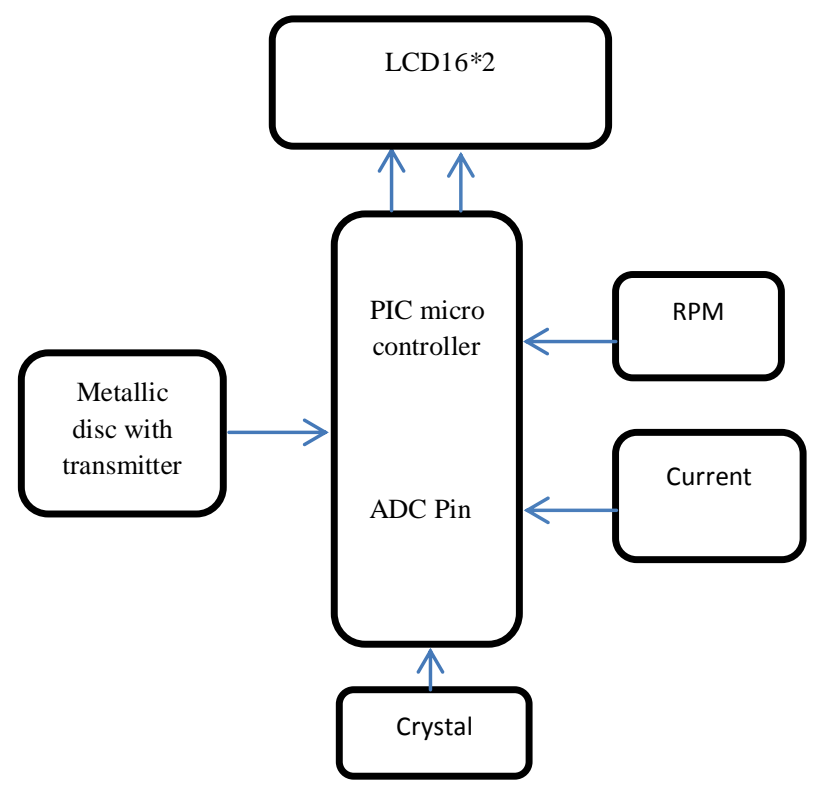

Fig.2 Block Diagram

\section{COMPONENT DESCRIPTION}

IV]1. Microcontroller PIC16F877A:

The embedded system used here consists of peripheral interface controller, PIC16F877A.Microchip the second largest 8 bit microcontroller supplier in the world is the manufacturer of the PIC microcontroller and a number of other embedded control solution. Pic16F877A is an open loop peripheral controller. Program to find out the speed and torque are written in this microcontroller. It is an 8 bit controller. It is having 40 pins. The operating frequency is $20 \mathrm{MHz}$. flash memory is 14.3kb.Data SRAM is 386bytes.The PIC16F877 CMOS FLASH based 8 bit microcontroller is upward compatible, the PIC16C5x, PIC12Cxxx and PIC16C7x devices. Its features self-reprogrammable under software 
control, 200ns instruction execution, 256byts of EEPROM data memory, an ICD, 2 comparators, 8 channels of 10 bits analog to digital (A/D) converter, 2 capture/compare/PWM functions, a synchronous serial port that can be configured as either 3 wire SPI or 2 wire I2C bus, USART and a parallel slave port.

\section{IV]2. IR Transceiver:}

An infrared transceiver, or IR transceiver, is capable of both sending and receiving infrared data. In other words an IR transceiver is a transmitter and a receiver housed together in one single unit and having circuitry in common. IR transceivers are often used for portable or mobile use. Some transceivers can do both functions at the same time, while other transceivers can only do one function at a time. The device may either have a focused beam, thus requiring it to be in a precise position in order to function properly, or it may be a broader beam, depending on the applications that it is designed for.

There are many different kinds of infrared transceivers and at Future Electronics we stock many of the most common types categorized by speed, size, supply voltage, link, data rate, packaging type and maximum idle current.

\section{IV]3. Current Sensor}

The Allegro ACS75x family of current sensors provides economical and precise solutions for current sensing in industrial, automotive, commercial, and communications systems. The device package allows for easy implementation by the customer. Typical applications include load detection and management, power supplies, and overcurrent fault protection. The device consists of a precision, low-offset linear Hall sensor circuit with a copper conduction path located near the die. Applied current flowing through this copper conduction path generates a magnetic field which is sensed by the integrated Hall IC and converted into a proportional voltage. Device accuracy is optimized through the close proximity of the magnetic signal to the Hall transducer. A precise, proportional voltage is provided by the lowoffset, chopper stabilized BiCMOS Hall IC, which is programmed for accuracy at the factory. The output of the device will be valid when the current flows from pin 4 to pin 5 . The internal resistance of this conductive path is typically 100 , providing low power loss. The thickness of the copper conductor allows survival of the device to $5 \times$ overcurrent conditions. The terminals of the conductive path are electrically isolated from the sensor leads (pins 1 through 3 ). This allows the ACS75x family of sensors to be used in applications requiring electrical isolation without the use of optoisolators or other costly isolation techniques.

\section{DESIGN AND CALCULATION}

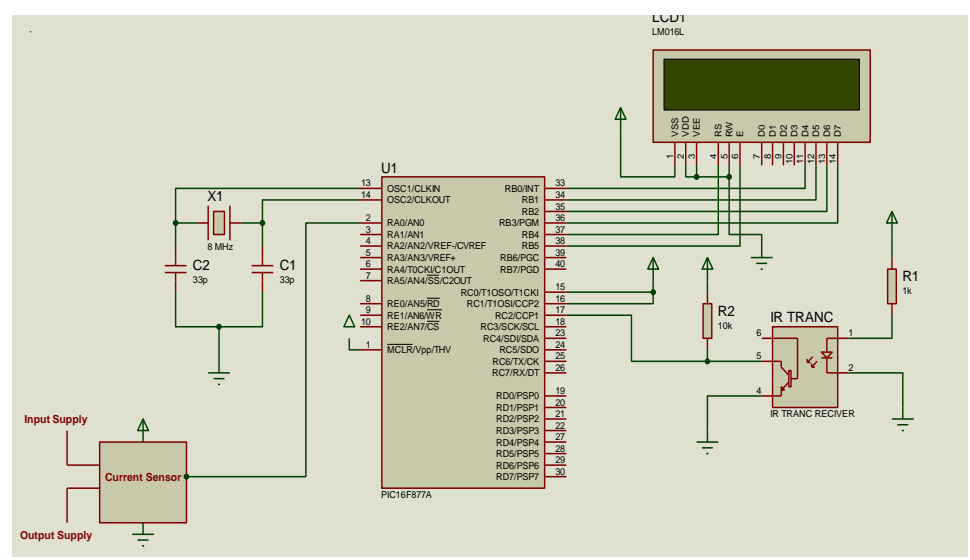

Fig.3 Circuit Diagram

\section{Calculating Full-load Torque:}

Full-load torque is the torque to produce the rated power at full speed of the motor. The amount of torque a motor produces at rated power and full speed can be found by using a horsepower-to-torque conversion chart. When using the conversion chart, place a straight edge along the two known quantities and read the unknown quantity on the third line.

\section{To calculate motor full-load torque, apply this formula:}

$\mathbf{T}=$ torque (in lb-ft)

$$
T=H P \times 5252
$$


Example: What is the FLT (Full-load torque) of a 30HP motor operating at $1725 \mathrm{rpm}$ ?

$$
\begin{gathered}
\mathbf{T}=\mathbf{H P} \times \mathbf{5 2 5 2} \\
\mathbf{r p m} \\
\mathbf{T}=\mathbf{3 0 \times 5 2 5 2} \\
\mathbf{1 7 2 5} \\
\mathbf{T}=\mathbf{1 5 7 , 5 6 0} \\
1725 \\
\mathbf{T}=\mathbf{9 1 . 3 4 \mathrm { lb } - \mathrm { ft }}
\end{gathered}
$$

Put these formulas to display...

$\Rightarrow$ Efficiency $=($ torque* speed $) /($ voltage* current $)$

$\Rightarrow$ Torque $=(\mathrm{HP} * 5250) /($ speed or RPM $)$

Using above 3 parameters.

HP can be calculated from motor watt rating.

Display following parameters on LCD:

1.Voltage

2.Current

3.Torque

4.Efficiency

5.Speed/RPM

\section{REFERENCES}

[1] John S.Hsu, Pedro J. Otaduy, John D. Kueck, "Efficiency and Reliability Assessments of Retrofitted High Efficiency Motors" Conference Record of 1995 IEEE30th IAS Annual Meeting, October, 1995, Oriando, Florinda, pp.2745-51

[2] J. D. Kueck, M.Olszewski, D. A.Casada, J.S. Hsu,P. J.Otaduy, L.M.Tolbert, “Assessment of Methods for Estimating motor Efficiency and Load under Field Condition,”ORNL/TM-13165,January1996, Lockeed Martin Energy Research Corp.

[3] Motors and Generators, NEMA MGI2003, Standard2003

[4] K. Gulez, A. A. Adam, and H. Pastaci, "A novel direct torque control algorithm for IPMSM with minimum harmonics and torque ripples," IEEE/ASME Trans. Mechatronics, vol. 12, no. 2, pp. 223-227, Apr. 2007.

[5] V. C. Gungor and G. P. Hancke, "Industrial wireless sensor networks: Challenges, design principles, and technical approaches," IEEE Trans. Ind. Electron., vol. 56, no. 10, pp. 4258-4265, Oct. 2009.

[6] Abel C. Lima-Filho "Embedded system integrated into a wireless sensor network for online dynamic torque and efficiency monitoring in induction motors" IEEE/asme transactions on mechatronics, vol. 17, no. 3, june 2012 